\title{
Strengths and deficiencies of beverage labelling regulations of Sri Lanka
}

\author{
Charith Amidha Hettiarachchi ${ }^{1 *}$, SM Arnold ${ }^{2}$, Sumal Nandasena ${ }^{1}$ \\ ${ }^{1}$ National Institute of Health Sciences, Kalutara, Sri Lanka; ${ }^{2}$ Office of the Regional Director of Health Services, Colombo, \\ Sri Lanka \\ *Correspondence: dr.charith@gmail.com (iD https://orcid.org/0000-0002-7329-6581
}

DOI: https://doi.org/10.4038/jccpsl.v24i2.8148

Received on: 04 April 2018

Accepted on: 21 May 2018

\section{Introduction}

Law is a collection of rules and is considered somewhat like social power to control the people of the society. Law plays an important role in public health. 'Law' and 'public health' have an important relationship, whereas law is essential for the infrastructure and the functioning of public health. Public health services cannot function optimally unless it has a strong legal basis. Protection and promotion of public health is one of the functions of any government. Public health legislation is an important instrument, thus, most of the countries have enacted legislations pertaining to the health of people (1).

Legislation relating to food labelling is a tool to ensure food safety and prevent unhealthy effects from foods. Food Act, No 26 of 1980 of Sri Lanka defines 'food label' as a tag, brand, mark, pictorial or other description, either written, printed, stencilled, marked, embossed, or impressed on or attached to a container of food (2). A considerable proportion of Sri Lankan customers $(n=120,87 \%)$ is known to read labels regularly (3). Thus, the proper labelling would regulate the consumption pattern of consumers. Out of all consumers, 65\% $(n=59)$ bought products with nutrition labelling due to health consciousness (4).

Food Act, No 26 of 1980 is the main legislation to control food safety and hygiene in Sri Lanka (2). It had been amended by Food Act, No 20 of 1991 (5) and Food Act, 2011 (6). There are over 40 regulations made under Section 32 of the Food Act. The main food labelling regulation in Sri Lanka is Food (Labelling and Advertising) Regulations (1376/9) of year 2005, which was created under Section 32 of the Food Act (7). Food (Colour Coding for Sugar levels) Regulations of 2016 is the other labelling regulation (8). In addition to these, there are labelling provisions in Food (Milk Standard) Regulation of 1989, Food (Sweeteners) Regulation of 2003, Food (Flavouring Substances and Flavour Enhancers) Regulation of 2013, Food (Bottled and Packed) Regulation of 2005, Food (Preservatives) Regulation of 1990 and Food (Colouring substances) Regulation of 2006 (9-14).

Other than the legal requirements in the Food Act, internationally accepted standards such as Codex Alimentarius standards help to improve the quality of food labels. Codex Alimentarius Standards is the name given for international food standards developed by the World Health Organization (WHO) and Food and Agricultural Organization (FAO) of the United Nations in 1963 (15). It is to protect consumer health and promote fair practices in food trade, and consists of science-based recommendations in all areas related to food safety and quality. Codex standards serve as a benchmark for national food legislations in many countries. It covers food labelling, food hygiene, food additives, pesticide residues and procedures for assessing the safety of foods derived from modern biotechnology (15). The Codex standards that mainly aim at labelling are General Standards for the Labelling of Pre-packaged Foods, General Guideline on Claims, Guidelines on Nutrition Labelling, General Standards for the Labelling of and Claims for Pre-packaged Foods for Special Dietary Uses, Guidelines for Use of Nutrition and Health Claims, Standard for Milk Powders 
and Cream Powder, General Standards for Bottled/ Packed Drinking Waters, Standard for Natural Mineral Waters and General Standards for Fruit Juices and Nectars (16-23).

Codex Alimentarius standards form the basis for national guidelines in various countries (22). It is important to review the provision of Sri Lankan labelling regulations with the international standards in order to identify strengths and deficiencies. Deficiencies need to be addressed by the policy makers when amending regulations periodically. The present review aims to describe the strengths and deficiencies in beverage labelling regulations of Sri Lanka relative to Codex Alimentarius standards.

\section{Methods}

Strength and weakness of Sri Lankan regulations were identified by comparing with the Codex standards. Strength was identified when a provision is described in both Sri Lankan regulations and Codex standards. Further, a context which is not covered in the Codex standard but available in the Sri Lankan standard was considered as strength. Weakness was identified when a standard in the Codex was not stated in the Sri Lankan regulations. Both Sri Lankan regulations and Codex standards are expected to be updated as amendments or revisions, and therefore it is presumed that outdated provisions do not exist in both categories.

A check list was developed based on the Codex standards and Sri Lankan regulations. This was developed based on broad areas of definitions of terms, general characteristics of the label, characteristics of the supplementary label, presenting language, general characteristics of information, common name, brand name/trade mark, ingredients, adherence to special standards given, net content, names and addresses, country of origin for imported beverages, batch number/lot number, 'date of markings' (manufactured and expiry dates), specific instructions, treatment of ionizing radiation, general claims, nutrient declaration, special provisions for fruit based drinks, and special provisions for milk and water.

Above broad areas were decided based on the subject areas of Codex standards and Sri Lankan regulations. Each broad area was further divided into sub areas based on standards and regulations. Content validity of the tool was assessed by a consultant community physician (CCP) and by an attorney-at-law (AAL). Content analysis was done.

The principal investigator (PI) initially reviewed and compared the Sri Lankan regulations with the Codex standards. An independent review was done by the AAL. Next, the PI's review was compared with the AAL's review by a CCP.

\section{Results}

Results were organized under sub-sections namely (1) general conditions and definitions, (2) components of the label (3) claims (4) fruit-based drinks, milk products and bottled water. Table 1 shows the strengths and weaknesses in the Sri Lankan regulations relevant to general conditions of labels and definitions. The general conditions include mandatory labelling, separable label, clearness, language and the quality of information provided. Sri Lankan regulations do not mention that the label should be inseparable. When the largest surface area is less than $10 \mathrm{~cm}^{2}$; list of ingredients, lot number, date marking, storage instructions and usage instructions are not required under the Codex standards with the exception of spices and herbs. The beverages that weighed, counted or measured in the presence of the purchaser are completely exempted from labelling by Sri Lankan regulations.

One of the weaknesses of Sri Lankan regulations when compared to Codex was using several technical terms without their definitions. In the definition of 'food', Codex excludes cosmetics, tobacco and substances used only as drugs: such exclusion do not include in the definition of 'food' in the Sri Lankan regulations. Strengths and weaknesses in Sri Lankan regulations relevant to definitions are also presented in Table 1.

Table 2 shows the strengths and weaknesses in Sri Lankan regulations relevant to the components of the label which are the common name, brand name, net content, ingredients, name and addresses, date markings, storage and usage instructions. Sri Lankan regulations have failed to mandate hypersensitivity warnings of ingredients if available. However, the location, language, font type and font size are regulated only in Sri Lankan regulations. 
Table 1. Strengths and weaknesses in the Sri Lankan regulations based on general conditions of labels and definitions

\begin{tabular}{l} 
Strengths \\
\hline Present only in Sri Lankan regulations \\
- The labelling is made mandatory and should display \\
conspicuously \\
- A uniform definition is present for 'claim' where as \\
Codex have two definitions in two different standards \\
- The 'common name' and 'main panel' are defined
\end{tabular}

\section{Present both in Sri Lankan regulations and Codex} standards

- Type of language is regulated

- Label should clearly have displayed

- Prohibited false, misleading, deceptive, erroneously impressed information

- Defined 'food', 'label', 'claim’, 'fruit juice’, 'fruit nectar', 'nutrient content claim', 'nutrient functional claim', 'natural mineral waters' and 'bottled/packed drinking waters'

\section{Present only in Codex standards}

- Label shall be applied in a manner that it will not become separated from the container

- Prohibits information confuse with other products

- Certain information of the label is exempted whereas some food products are exempted completely from labelling by Sri Lankan regulations

- The terms 'consumer', ‘container', ‘date of manufacture', 'use by date', 'sell by date' and 'date of minimum durability' 'Food additive', 'ingredients', 'nutrition labelling', 'lot’, 'pre-packed’, 'processing aid', 'food for catering purpose', 'nutrient declaration', 'nutrient', 'Polyunsaturated fatty acids', 'trans fatty acids', 'dietary fibre’, 'concentrated fruit juice’, 'liquid medium', 'health claim’and ‘nutrition claim’ are defined

\section{Table 2. Strengths and weaknesses in the Sri Lankan regulations relevant to components of the label}

\begin{tabular}{cc}
\hline Strengths & Weaknesses \\
\hline
\end{tabular}

\section{Present only in Sri Lankan regulations}

- The boldness and size of letters/digits are regulated

- The symbol of ionizing radiation is mandatory

- Requires manufactured/ expiry/ repacked dates

- Country of origin made compulsory for imported foods whereas in Codex it is required only if its omission would mislead

- The location of the common name, brand name and net content are regulated

Present both in Sri Lankan regulations and Codex standards

- Required the manufacturer, packer or distributor

- Required ingredients to display as a list

- Order of the ingredient list is regulated

- Presenting 'unit' of net content is regulated

- The storage and usage instructions should display if any

- Display of statement on ionizing radiation

- Date format (e.g. DD/MM/YY) is mandatory

- Some food is exempted for date of expiry (in Sri Lankan) or date of minimum durability (in Codex)

- Required the manufacturer, packer or distributor

\section{Present only in Codex standards}

- Display of quantity of ingredients, sub ingredients and hypersensitivity warnings are mandatory

- Required for the importer and exporter

- Requires the date of minimum durability (Date of minimum durability is not similar to the expiry date)

- Required ingredients to be displayed under the title of 'ingredients'

- Standard name as the common name if available under codex or local regulations

- The brand name to be accompanied the common name

- Required the common name to be specific and indicates true nature

- $\quad$ Nutrient declaration is mandatory 
Comparison was done in relevance to names and addresses of the manufacturer and distributor; date of marking and batch number. The details are presented in Table 2. The Sri Lankan regulations do not require the indication of the foreign manufacturer and the importer in the imported beverages. The manufactured, expiry and repacked dates are not stated in the Codex guidelines and require only the 'date of minimum durability'. The date format is regulated only in the Sri Lankan regulations. Table 2 also shows the strengths and weaknesses in Sri Lankan regulations relevant to information on storage and usage, ionizing radiation and nutrient declaration. Nutrient declaration is not mandatory in the Sri Lankan regulations.

There is a major difference between regulations of claims. Both strengths and weaknesses prevail, as shown in Table 3. Both state about claims, which are prohibited and can be made if only certain conditions are fulfilled. However, the claims mentioned under each type are not similar.

The strengths and weaknesses in relevance to fruitbased drinks, milk products and bottled water are presented in Table 4. The sugar content, logo, colour, font size and language are some of the features compared. Codex requires the fat content of milk to be displayed whereas Sri Lankan regulations require more information such as information on preparation the milk. The colour code for the sugar level needs to be displayed only under Sri Lankan regulations.

Table 3. Strengths and weaknesses in the Sri Lankan regulations relevant to claims

\begin{tabular}{ll}
\hline Strengths & Weaknesses \\
\hline
\end{tabular}

\section{Present only in Sri Lankan regulations}

- The terms 'pure', 'natural', nutrient content claim, adequate source for one or more nutrients, protein source, energy provider, enriched, and contain of carbohydrates, vitamins or minerals can be displayed under certain conditions

- False or misleading claims, claims that indicates contain restorative or medicinal properties which beneficial for invalids, cure alleviate or prevent any illness; aid for slimming, weight control, weight reduction; claiming dietary fats are protection against heart diseases are prohibited

- The nutrition functional claim, fortification and recommendation by a professional association can be displayed only under approval of Chief Food Authority

\section{Present only in Codex standards}

- The terms 'Adequate source of all nutrients', 'balanced diet', 'ordinary food cannot supply adequate amounts of all nutrients', claims which cannot be substantiated, 'prevent or cure diseases', and claims which give rise to doubt about the safety of similar foods are prohibited

- Increased or special nutrition value, special nutrition qualities, special characteristics, claims which highlight absence or non-addition of particular substances, claims which highlight absence or non-addition of particular nutrients, nutrition or health claim, nutrient content claim, comparative claims, non-addition of sugars, non-addiction of Sodium salts, claims related to dietary guidelines, and Vitamin claim can be displayed under certain conditions

- The terms such as 'natural', ‘pure', 'fresh', 'homemade', 'organically grown', 'biologically grown', 'religious', 'free of salt,' 'healthy diets', or 'ritual claim' can be displayed under certain conditions 


\section{Table 4. Strengths and weaknesses in the Sri Lankan regulations relevant to fruit-based drinks, milk products and bottle water}

Strengths

\section{Present only in Sri Lankan regulations}

- In fruit-based drinks the logo for sugar level, numerical description of sugar content, description of relative sugar level and colour code for sugar level are regulated

- Specific declarations relevant to content, usage and the method of presentation in milk products are mandatory

\section{Present only in Codex standards}

- Required standard names given for fruit-based drinks and milk products

- Requires a declaration of milk fat content and milk protein

\section{Discussion}

Sri Lanka, being a Codex member country since 1972 had followed the Codex standards in developing labelling regulations. However, Sri Lankan regulations are not similar in all aspects of the Codex standards.

The Codex standards are properly organized under main headings/components such as names of the beverage, ingredients, net content, name and addresses, country of origin, date marking, and instructions for use. Hence, Codex standards are simple, clear and user-friendly. However, Sri Lankan regulations are not organized under headings/components. All regulations relevant to one component cannot be found in one place. It is necessary to read the entire gazette to obtain knowledge even in one component. One general regulation may have been restricted by another specific regulation which has been stated in a later place. Hence, the Sri Lankan regulations are difficult to understand by an ordinary person due to its complexity. This complexity is a common feature for most of the Sri Lankan legislation. However, Indian labelling regulations are simpler in this regard when compared to Sri Lanka. This may have led to non-adherence of beverage labels to regulations by the manufacturers/distributors as well as less number of prosecutions by authorized officers. Indian labelling regulations has been categorized according to the components similar in Codex, thus a user-friendly document when compared to the Sri Lankan one (23). There are several documents relevant to labelling in both Codex and Sri Lankan context. This leads to greater inconvenience to manufacturers and distributors as they have to refer several documents and are more likely to misinterpret and neglect the regulation. In contrast, the Indian regulations have concise all-inclusive labelling regulations in a single document, which is the Food Safety and Standards (Packaging and Labelling) Regulation 2011 (24).

Sri Lanka has adopted similar definitions as in Codex. However, a substantial number of definitions that been dropped from the Sri Lankan regulations. Terms such as 'ingredient', 'additive', 'nutrition claim', 'manufactured date', 'expiry date' and 'date of repacking' have been used without giving them a definition. In contrast, the Indian regulations define the terms such as manufactured date and expiry date (24). Few definitions which are absent in the Codex are described in the Si Lankan regulations, such as the common name and main panel. Surprisingly, the key term 'food' is differently defined in Sri Lankan regulations and had included the term 'food' within the definition, which could confuse the reader (2). This confusion does not exist in Codex. Codex definition of 'food' is more precise as it excludes cosmetics, tobacco and substances used only as drugs (16), whereas in the absence of such exclusions, the scope of 'food' has become not clear in the Sri Lankan regulations. Furthermore, meaning of the term 'best before' is similar to 'expiry date' in the Sri Lankan regulations, which is another deviation from the Codex where the term 'best before' is similar to the 'date of minimum durability’.

Definition of 'claim' in the Sri Lankan regulation has been adopted from the Codex general standards for the labelling of pre-packed foods. Simply, it is a 
particular quality of a food/beverage. Unfortunately, the term 'particular quality' is not defined and as a result, this term is vague and reflects a wide range of qualities. Because of this reason, it is uncertain that some representations in some labels are claims or not. This is a disadvantage for authorized officers and an undue advantage for the manufacturers. 'Nutrient functional claim' is a subtype of 'health claims' in the Codex but in Sri Lankan regulations, it is a subtype of 'nutrition claims' deviating from the Codex standards.

Sri Lankan regulations have identified a 'main panel' of the label; hence labels can be divided in to two components as the main panel and other panels. Using this effectively, Sri Lankan regulations have been able to regulate the location of information in the label. For an example, brand name, common name and net content should be given in the main panel. Therefore, labels show some uniformity and this is clear and convenient to consumers. This demarcation of the label is not identified in Codex. However, Sri Lankan gazette gives two different meanings to the main panel. Section 2 of the regulation states that the label should be in the main panel, which indicates that the main panel is part of the container surface. In contrast, Section 14 states that the main panel is part of the label. These terminologically controversial points should be avoided in legal documents. According to the Indian regulations, the 'principal display panel' which has a similar meaning to the 'main panel' in Sri Lanka however is defined as part of the container. United States have taken further steps, by introducing 'alternative display panels' and 'information panels' (25). Labelling regulations in the United Kingdom require the 'use by date' (other than name of the food, warnings and quantity) to be displayed in the 'front of packaged food' (26) which is then easier for the consumer to see the expiry date at a glance, as the expiry date is one of the important determinants at the time of purchase. However, in Sri Lanka the expired date can be displayed in any panel, hence it is not uncommon to see the consumers turn all-round the container to find the expiry date.

Importantly, the Sri Lankan regulations have regulated the font size, the font type of digits and letters which have not been done in the Codex. Thus, the information in Sri Lankan beverage labels is expected to be very clear to the consumers. It is interesting to note that Indian regulations regulate the width of the letters as well.
Codex allows omitting the display of ingredients in single ingredient products, whereas the Sri Lankan regulations do not. This non-omission seems unrealistic for products such as bottles of water but may be important for products such as tea and coffee, for which the single ingredient usage is uncertain.

It is commonly accepted that a label shall be applied in a manner that it will not become separated from the container. This important requirement is not stated in the Sri Lankan regulations and is not uncommon to see partially separated labels in the Sri Lankan beverage market. Codex has included this fact in its guidelines. The Codex also regulates labelling of the outer wrapper (when the container is covered with a wrapper). This is not addressed in the Sri Lankan regulations. The regulations are also ignorant in the case of labelling of a large container or package, where small food packages or containers are stored - a condition commonly seen in toffee products.

Nutrient declaration and hypersensitivity details of the ingredients are not compulsory under Sri Lankan regulations: but are important as health information with direct effects on the health of consumers. The United Kingdom has also required the display of cooking instructions (other than the usage and storage instructions) and warnings if any (26), which are not considered in both Sri Lankan regulations and Codex standards.

The traffic light labelling system has been suggested by various experts and organization for sugar, salt and fat (27). Currently, Sri Lanka has implemented this for sugar levels but is confined to carbonated drinks and fruit-based drinks. The Sri Lankan regulations are strong in this regard. India has introduced a traffic light labelling system for vegetarian foods (24). It is possible to introduce a traffic light labelling system for salt and fat as well: but too many labelling may confuse the consumer. However, expanding the Sri Lankan traffic light labelling on sugar levels to capture milk-based sweetened products, jams, biscuits and chocolates would be benefited.

One of the drawbacks of Sri Lankan regulations is the difference between English and Sinhala translations. For example, the common name should be given only in two languages according to the Sinhala gazette, but it should be in at least two languages according to the English Gazette. English wordings 
seem to be more appropriate. The Food Act states that the Sinhala version prevails in case of disparity between Sinhala and Tamil versions but does not answer the disparity between Sinhala and English versions (2). However, Sinhala version is prevailed in the case of disparity between Sinhala and English versions according to Sri Lankan case law (28).

A few vague regulations have confused the labelling laws in Sri Lanka. Section 4 (3) states that "provision of this regulation shall not apply to prepacked food products the weight of which does not exceed 25 grams, provided the dispenser package or container from which they are customarily sold to the buyer is labelled according to this regulation”. This regulation does not seem to have any sensible meaning and should be elaborated by an example. Therefore, application of labelling regulations to food products that do not exceed $25 \mathrm{~g}$ is unclear, which is a practically impossible task to include all required information in such small containers.

Another important drawback is that the Sri Lankan labelling regulations have been limited to food/beverage under 'sale'. In section 2 of the Food (Labelling and Advertising) Regulations 2005, it is worded as "no person shall offer for sale, expose or keep for sale, transport or advertise for sale, any food contained in a package or container unless such package or container is labelled in accordance with these regulations" (7). This very clearly excludes food/beverages that are distributed free of charge. This issue has risen because of applying the term 'for sale' repeatedly. Therefore, food/beverages that are distributed free of charge by the government (e.g. 'Thriposha' food supplement) or private sector (e.g. social welfare occasions, disaster situations.) are not under the labelling regulations. However, it should be kept in mind that even if these are excluded of labelling regulations, free distributions are regulated by the Food Act (2). Codex does not confine to the food for 'sale' (16). In the Indian regulation, it is stated as "every pre-packed food shall carry a label”, which also does not confine to food for sale (24).

\section{Conclusions and Recommendations}

Sri Lankan labelling regulations have followed some of the basic guidelines of Codex Alimentarius while some regulations have not. The Codex categorization for claims has not been followed, instead of incorrectly categorized in Sri Lankan regulations. Sri Lanka has strong regulations on labelling though there are controversial and poorly defined areas and deficiencies that need to be attended to as early as possible. Thus, it is a public health challenge to address and develop regulations simply with clear labelling provisions after scientific revision of the existing regulations.

\section{Public health implications}

Sri Lankan labelling regulations need to be revised periodically to meet the emerging health challenges and be updated according to international standards. This review provides that opportunity to the authorities. Legislative weaknesses which dramatically affect the quality of food labels have been disclosed in this study, which can be corrected by an amendment. Addressing the legislative issues in the Sri Lankan labelling regulations that have been identified in this study will help authorized officers for smooth legal proceedings and will be beneficial for the health of consumers, and in turn contributing to a healthier nation.

\section{Author Declarations}

\section{Competing interests: None.}

Ethics approval and consent to participate: Ethical approval was obtained from the National Institute of Health Sciences Kalutara (Reference No. NIHS/ERC/ 16/36).

\section{Funding: Self-funded}

Acknowledgements: Dr Chintha Gunaratne (MBBS, $\mathrm{MD}$ ) and Mr WA Chandrasiri (LLB, AAL) for assessing the content validity of the tool. Mr Michael Dias (LLB, AAL) who did the independent review and Dr Lakmini Magodaratne (MBBS, MD) who compared the PI's desk review with the lawyer's review.

Author contribution: CAH reviewed the literature, compared the Sri Lankan regulations with Codex standards and wrote the manuscript. SMA and SN reviewed the scientific process. 


\section{References}

1. Ministry of Health. Manual for the Sri Lanka Public Health Inspector. Colombo: State Printing Corporation, 2010.

2. Ministry of Health. Food Act, No 26 of 1980. Colombo: Government Publication Bureau, 1980.

3. Senarath S, Karunagoda R. Consumer attitude towards labelling of genetically modified foods in Sri Lanka. Tropical Agricultural Research 2012; 23(3): 283-288. Available from: https://tar.sljol.info.

4. Prathirajja P. Ariyawardana A. Impact of nutritional labelling on consumer buying behaviour. Sri Lankan Journal of Agricultural Economics 2003; 5: 35-46. Available from: https://sjae.sljol.info.

5. Ministry of Health. Food (Amendment) Act of 1991. Colombo: Government Publication Bureau, 1991.

6. Ministry of Health. Food (Amendment) Act of 2011. Colombo: Government Publication Bureau, 2011.

7. Ministry of Health. Food (Labelling and Advertising) Regulations of 2005. Colombo: Government Publication Bureau, 2005.

8. Ministry of Health. Food (Colour coding for sugar levels) Regulations of 2016. Colombo: Government Publication Bureau, 2016.

9. Ministry of Health. Food (Milk Standards) Regulations of 1989. Colombo: Government Publication Bureau, 1989.

10. Ministry of Health. Food (Sweeteners) Regulations of 2003. Colombo: Government Publication Bureau, 2003.

11. Ministry of Health. Food (Flavouring Substances and Flavour Enhancers) Regulations of 2013. Colombo: Government Publication Bureau, 2013.

12. Ministry of Health. Food (Bottled and Packed Water) Regulations of 2005. Colombo: Government Publication Bureau, 2005.

13. Ministry of Health. Food (Preservative) Regulations of 1989. Colombo: Government Publication Bureau, 1989.

14. Ministry of Health. Government of Sri Lanka. Food (Colouring substances) Regulation of 2006. Colombo: Government Publication Bureau, 2006.

15. Codex Alimentarius Commission. International Food Standards. Codex Alimentarius Commission, 2015. Available from: http://www.codexalimentarius.net.

16. Codex Alimentarius Commission. General Standard for the Labelling of Pre-packaged Foods. Codex Alimentarius Commission, 2015.

Available from: http://www.codexalimentarius.net.

17. Codex Alimentarius Commission. Guidelines on Nutrition Labelling. Codex Alimentarius Commission, 2015.

Available from: http://www.codexalimentarius.net.

18. Codex Alimentarius Commission. General Guidelines on Claims. Codex Alimentarius Commission, 2015. Available from: http://www.codexalimentarius.net.

19. Codex Alimentarius Commission. Guidelines for Use of Nutrition and Health Claims. Codex Alimentarius Commission, 2015.

Available from: http://www.codexalimentarius.net.

20. Codex Alimentarius Commission. Standard for Milk Powders and Cream Powder. Codex Alimentarius Commission, 2015.

Available from: http://www.codexalimentarius.net.

21. Codex Alimentarius Commission. General Standards for Bottled/Packed Drinking Waters. Codex Alimentarius Commission 2015.

Available from: http://www.codexalimentarius.net.

22. Codex Alimentarius Commission. Standard for Natural Mineral Waters. Codex Alimentarius Commission, 2015. Available from: http://www.codexalimentarius.net.

23. Codex Alimentarius Commission. General Standards for Fruit Juices and Nectars. Codex Alimentarius Commission, 2015.

Available from: http://www.codexalimentarius.net.

24. Food Safety and Standards Authority of India. Food Safety and Standards (Packaging and Labelling) Regulation of 2011. Food Safety and Standards Authority of India, 2011.

Available from: http://www.fssai.gov.in.

25. United States Food and Drug Administration. Fair Packaging and Labelling Act of 1967. Food and Drug Administration, 1967.

Available from: http://www.fda.gov.

26. Government of United Kingdom. Food Labelling and Packaging. Government of United Kingdom, 2015. Available from: https://www.gov.uk.

27. The Guardian. Food packaging 'traffic lights' to signal healthy choices on salt, fat and sugar, 2013. Available from: https://www.theguadian.com.

28. Lawnet. Pinto v Trelleborg Lanka (Pvt.) Ltd. and others. Sri Lanka Law Reports, 2013.

Available from: http://www.lawnet.gov.lk. 